\title{
EDITORIAL
}

\section{Starting inhaled corticosteroids in asthma: when, how high, and how long}

\author{
T. van der Molen*, H.A.M. Kerstjens ${ }^{+}$
}

In the past 10 years many intervention studies have tried to define the optimal dose of inhaled corticosteroids in the treatment of patients with mild or moderate asthma. In all but the largest studies it has been very difficult to show a dose related effect on common outcome parameters such as symptoms and lung function. Relevant differences not only in end-parameters but also in study designs, and patient selections have made it difficult to compare individual study results. Despite the confusions, guideline committees and leading scientists have tried to advise clinicians about the dosage of inhaled corticosteroids that they should prescribe to their patients. It is not surprising that these advices still differ or are rather vague [1-3]. For the clinician many important questions remain: 1) when to start with an inhaled corticosteroid in patients with asthmatic symptoms; 2) is starting high and then stepping down with inhaled corticosteroids more efficacious than the step up method; 3 ) is there a real requirement for the monitoring of symptoms, lung function, or inflammation in order the maintain the best results in the treatment of patients?; and 4) once therapy is started, how long should it continue?

In this issue of the European Respiratory Journal (ERJ) two of these questions come closer to an answer: is an initial high dose (step down treatment) of an inhaled corticosteroid beneficial for patients with mild or moderate asthma; and, do clinicians have to start earlier with inhaled corticosteroids, i.e. at the moment that bronchial inflammation causes airway responsiveness without asthma like symptoms.

GERSHMAN et al. [4] report a study in which patients with asthma received treatment with a low $\left(100 \mu \mathrm{g} \cdot\right.$ day $\left.^{-1}\right)$ or a high dose $\left(1,000 \mu \mathrm{g} \cdot\right.$ day $\left.^{-1}\right)$ of fluticasone propionate (FP) 6 weeks followed by placebo for 3 weeks. All patients had asthma with markedly reduced lung function and had not used steroids for at least 6 weeks prior to the study. Outcome parameters included parameters of inflammation such as provocative concentration of methacholine causing a $20 \%$ fall in forced expiratory volume in one second (FEV1; PC20), sputum eosinophil cationic protein (ECP), tryptase, and eosinophils, as well as the common parameters such as symptoms and lung function. Of the parameters, only the sputum eosinophils and

*Dept of General Practice, and ${ }^{+}$Dept of Pulmonology, University of Groningen, the Netherlands.

Correspondence: T. van der Molen Dept of General Practice University of Groningen A. Deusinglaan 49713 AW Groningen The Netherlands Fax: 31503619320 salbutamol use for the relief of symptoms decreased more in the high dose group than in the low dose group. All other parameters showed no statistical differences between groups. After cessation of the active treatment, improvements in FEV1 and PC20 quickly reversed in both groups, but the improvements in peak flow and tryptase persisted for at least 3 weeks. The current authors agree with Gershman et al. [4] that the dose response effects were difficult to demonstrate because low dose FP was quite effective.

The lack of differences between groups in this study could be interpreted as a result opposing the step down method for starting with inhaled corticosteroids. When in a group of steroid naive patients with asthma with clear symptoms and markedly reduced lung function no benefit has been shown of a 10-fold dose of FP there are no objective reasons to start with a high dose of inhaled corticosteroids in mild or moderate asthma. This view is compatible with some earlier studies investigating a start high approach. In a study conducted in Groningen, the Netherlands the investigators selected steroids naive patients with newly detected asthma from their General Practice [5]. Patients were selected because their symptoms and $\beta$-agonist use urged the general practitioner to prescribe inhaled corticosteroids according to the guidelines. Patients were treated with 100 or $400 \mu \mathrm{g}$ budesonide b.i.d. for 4 weeks followed by 8 weeks of $200 \mu \mathrm{g}$ budesonide $o . d$. In this study the high start approach over a fixed period was compared with a low dose treatment in a total of 84 patients. There were no differences between groups in the common outcome parameters such as symptoms, lung function and $\beta$-agonist use for the relief of symptoms. The study of GERSHMAN et al. [4] shows again that there is no hard evidence to advise clinicians to treat all their newly detected steroid naive patients with asthma with an initial high dose of inhaled corticosteroids. Only a few of these patients, and presumably merely the patients with severe asthma, will benefit from an initial high dose of inhaled corticosteroids. Furthermore, in the office of the busy clinician it is, unfortunately, highly probable that patients will be not tapered off from their dosage of inhaled corticosteroids.

There are now several studies making the point that delayed institution of inhaled steroids can negatively influence the maximal response obtained in adults and children with established disease [6-8]. The study by CONVERY et al. [9], also published in this issue of the ERJ, addressed the problem of treating patients with inflammation without clear symptoms and signs of asthma. They selected subjects with airway responsiveness from an 
epidemiological study. Subjects were asymptomatic and were not diagnosed as having asthma. They were steroid naive. A total of 52 subjects received 2,000 $\mu \mathrm{g}$ FP or placebo for a period of 6 weeks. Subjects were followed until 20 weeks after completion of the treatment phase. The study showed that over the 6 weeks there was a steadily increasing beneficial effect on the level of airway responsiveness from FP, but this was no longer evident 2 weeks after the treatment stopped. The consequences of the paper are not very easy to determine. Subjects without complaints and with normal lung function were selected on the basis of airways hyperresponsiveness. The latter was also the only parameter to improve with therapy. The relation of airways hyperresponsiveness to inflammation and, perhaps in this context more importantly, airways remodelling is less than clear. The first studies incorporating bronchial biopsies in the epidemiological setting of bronchial hyperresponsiveness have been started in order to further elucidate this point. From a clinical point of view, the authors are eagerly awaiting the results of studies looking at the effects of long term inhaled steroids ( $5 \mathrm{yrs}$ ) on lung function in very mild (or early?) asthmatics.

The findings in the studies by GERSHMAN et al. [4] and CONVERY et al. [9] that the effects of inhaled steroids wear off very quickly, at least after short term therapy, are not new [10] but are certainly worth reiterating. It is important to realise that the time course of improvement in symptoms and lung function (days to weeks) is generally much quicker than the improvement in airway hyperresponsiveness. It has been shown that although the largest part of the improvement in hyperresponsiveness occurs within 3 months, further improvements can continue for at least $1 \mathrm{yr}[11,12]$. Together, these results question the rationale of short bursts of inhaled steroids in all but the mildest cases. In the management of mild asthma this is a very important conclusion. Even patients with mild or presymptomatic asthma and airway responsiveness should when treated with inhaled corticosteroids, be monitored for a longer period of time and encouraged to continue their treatment in order to maintain the beneficial effect.

Finally, what tools should be used to monitor improvement and guide potential dose reduction or even cessation? Airways hyperresponsiveness seems to be a good parameter since it is amongst the first of the parameters to deteriorate after cessation of therapy. It has also been suggested to be a valuable addition in deciding upon doses of inhaled steroids [13]. However, it is not a very accessible tool for general practitioners and repeated monitoring of airways hyperresponsiveness, even in the clinical setting, is quite a task both for patients and for professionals. In day to day practice, the assessment of symptoms and perhaps peak flow will remain the most useful tools in monitoring patients with asthma.

\section{References}

1. Global initiative for asthma: a global strategy for asthma management and prevention. Bethesda, MD, USA, National Institutes of Health, 1995.

2. Anonymous. Asthma in adults and schoolchildren. Thorax 1997; 52 (Suppl. 1): S2-S8, S11-S15, S20-S21.

3. National Asthma Education and Prevention, N.I.H.L.B. Guidelines for the diagnosis and management of asthma. Expert Panel Report 2. Bethesda, MD, USA, Publ. No. 97-4051. U.S. Dept. of Health and Human Services, 1997.

4. Gershman NH, Wong HH, Liu JT, Fahy JV. Low dose and high dose fluticasone propionate in asthma; effects during treatment and after treatment is stopped. Eur Respir $J$ 2000; 15: 11-18.

5. van der Molen T, Meyboom-de Jong B, Mulder HH, Postman DS. Starting with a higher dose of inhaled corticosteroids in primary care asthma treatment. Am J Respir Crit Care Med 1998; 158: 121-125.

6. Haahtela T, Järvinen M, Kava T, et al. Effects of reducing or discontinuing inhaled budesonide in patients with mild asthma. $N$ Engl J Med 1994; 331: 700-705.

7. Agertoft L, Pedersen S. Effects of long-term treatment with an inhaled corticosteroids on growth and pulmonary function in asthmatic children. Respir Med 1994; 88: 373-381.

8. Overbeek SE, Kerstjens HAM, Bogaard JM, Mulder PGH, Postman DS, Dutch CNSLD Study Group. Is delayed introduction of inhaled corticosteroids harmful in patients with obstructive airways disease (asthma and COPD)? Chest 1996; 110: 35-41.

9. Convery RP, Leitch DN, Bromly CL, Ward RJ, Bartlett G, Hendrick DJ. Effect of inhaled fluticasone propionate on airway responsiveness in treatment-naive individuals: is lesser benefit in females a determinant for gender differences in asthma severity? Eur Respir J 2000; 15: 1924.

10. Vathenen AS, Knox AJ, Wisniewski A, Tattersfield AE. Time course of change in bronchial reactivity with an inhaled corticosteroid in asthma. Am Rev Respir Dis 1991; 143: 1317-1321.

11. Juniper EF, Kline PA, Vanzieleghem MA, Ramsdale EH, O'Byrne PM, Hargreave FE. Effect of long-term treatment with an inhaled corticosteroid (budesonide) on airway hyperresponsiveness and clinical asthma in nonsteroiddependent asthmatics. Am Rev Respir Dis 1990; 142: 832836.

12. Kerstjens HAM, Brand PLP, Hughes MD, et al. A comparison of bronchodilator therapy with or without inhaled corticosteroid therapy in obstructive airways disease. N Engl J Med 1992; 327: 1413-1419.

13. Sont JK, Willems LN, Bel EH, van Krieken JH, Vandenbroucke JP, Sterk PJ. Clinical control and histopathologic outcome of asthma when using airway hyperresponsiveness as an additional guide to long-term treatment. The AMPUL Study Group. Am J Respir Crit Care Med 1999; 159: 1043-1051. 